\title{
Effects of drying and shrinkage on the mechanical performance of unsaturated fine/medium- grained soils used as heat storage media
}

\author{
Henok Hailemariam ${ }^{1, *}$, and Frank Wuttke ${ }^{1}$ \\ ${ }^{1}$ Geomechanics and Geotechnics, Kiel University, Ludewig-Meyn-Straße 10, 24118 Kiel, Germany
}

\begin{abstract}
Studying the mechanical behavior of heat storage media is vital in the safety and design of most sensible and borehole thermal energy storage systems, which are normally built as part of the sub-structure of buildings with load bearing capabilities. In spite of its importance on the efficiency and performance of heat energy storage systems, the mechanical stability and behavior of heat storage materials, mainly at elevated temperatures, has not been given adequate attention in past studies. On this regard, the mechanical behavior of three unsaturated fine- and medium- grained soils from Germany is studied at elevated temperatures, in view of using the soils as a solid sensible heat storage media. The results show a significant dependence of the mechanical behavior of the investigated soils on moisture content and temperature. Furthermore, an increase in shrinkage of the soil specimens with a decrease in the texture of the soils was observed during heating of the soils. The shrinkage behavior is also corroborated with the formation of minor and moderate tensile desiccation cracks of the specimens, which when unaccounted for can result in the lowering of the heat conduction of the heat storage medium, thus lowering the efficiency of the heat storage system.
\end{abstract}

\section{Introduction}

Satisfying the global energy demand with clean and reliable energy is one of the primary challenges of the current century. In this regard, the field of geotechnical engineering has been making a significant contribution in solving the energy problem. One such example is via household and industrial seasonal storage of thermal energy using borehole thermal energy storage systems, BTES, (e.g. soils) or solid sensible heat storage systems (e.g. cemented porous media), where heat or cold from solar collectors or other sources of energy is stored for periods of up to several months for later use (Laing et al. 2006 [1]; Laing et al. 2012 [2]; Hailemariam et al. 2019 [3]).

Such systems are usually designed as part of the substructure of buildings and hence have load bearing capabilities. Therefore, accurate study of their mechanical stability at different moisture (due to fluctuations in ground water table level) and temperature (due to thermal loading and unloading of the system) conditions must be carefully investigated prior to the design and operation of the system.

Furthermore, the mechanical failure of the different components of the heat storage system, such as with the formation of cracks, due to an inappropriate design can have significant effects on the performance and overall efficiency of the heat storage system. Formation of micro- and macro-cracks can be evident particularly when soils with a fine-grained texture are used as the media for the storage of heat. The soils which are usually expected to have a high degree of water saturation (which will enable them to have a higher heat storage and conduction capacity), will typically exhibit shrinkage and drying particularly at areas closer to the heat exchanger due to their exposure to high temperatures and the subsequent migration of moisture.

The formation of cracks in the heat storage soils as a result will generally lower their effective thermal conductivity. The thermal conductivity of the heat storage medium controls the rate of loading or unloading of heat storage systems and their efficiency (Doughty et al. 1983 [4]; Hart \& Whiddon 1984 [5]). The lowering of the effective thermal conductivity of the heat storage medium will in turn slow the rate of heat transport toand-fro the heat exchanger interface, thus significantly reducing the system efficiency.

In this research, the mechanical performances of three fine- and medium- grained soils (with the view of being used as heat storage media) at different saturation levels and temperature conditions are studied experimentally. The research was conducted within the scope of project Angus II, which predominantly aims at developing small and large scale solar powered thermal energy storage systems for domestic and industrial applications. As the focus of the project is to study the geological subsurface of the Schleswig-Holstein area of northern Germany for the purpose of large scale

\footnotetext{
${ }^{*}$ Corresponding author: henok.hailemariam@ifg.uni-kiel.de
} 
underground heat storage, two glacial till soil types which are predominantly found in the area were selected to be investigated in this study. A third fine-grained soil from Thuringia, Germany, was also studied to compare and corroborate the data obtained from the till soils.

\section{Experimental program}

\subsection{Tested soils}

Two naturally occurring glacial till soils from the Hohe Ufer cliff of Heilingenhafen area in Schleswig-Holstein, northern Germany, and a silty clay soil from Thuringia, Germany, were used for the study. The first till soil (Fig. 1, left), with a comparatively younger age 'oberer Geschiebemergel, Weichselian' is referred to in this study as 'oM'. This till deposit is however a variation of or slightly different from the 'oberer Geschiebemergel' till deposit mentioned in the literature by Stephan (1985) [6]. The second till soil (Fig. 1, middle), with a comparatively older age or deposited earlier than the oM till is referred to in this study as 'mittlerer Geschiebemergel, Saalian' or ' $\mathrm{mM}$ ', and the silty clay soil (Fig. 1, right) is labeled as ' $\mathrm{SC}-\mathrm{A}$ ' in this study. Tables 1 and 2 show a summary of the obtained physical and geotechnical properties of the soils. Results of X-ray diffraction (XRD) mineralogical analysis on the three soils are shown in Fig. 2.

\subsection{Equipments used}

Figure 3 shows the one-dimensional compression testing equipments used to assess the moisture content and temperature dependent compressibility of the soils. In Fig. 3 (left), the set-up with a UL-25 loading machine (with a maximum force limit of $25 \mathrm{kN}$ ) for room temperature testing is shown. And in Fig. 3 (right), the set-up for elevated temperature testing, where an oedometer cell is fitted in to a UL-60 loading machine (with a maximum force limit of $60 \mathrm{kN}$ ) with a climate chamber, is shown.

\subsection{Experimental procedure}

The oedometric moisture and temperature controlled compression tests were performed with oedometer cells which were fitted with UL-25/60 loading devices and with a climate chamber unit for controlling specimen temperature.

The specimens were prepared with a diameter of 50 $\mathrm{mm}$ and a height of $20 \mathrm{~mm}$ making sure that the top and bottom faces of the specimens were perfectly flat to ensure proper contact with the base and loading piston. The tests were conducted at soil temperatures of 20, 40 and $60^{\circ} \mathrm{C}$. For the tests in fully saturated condition, sufficient time for ensuring full saturation of the specimens and for attaining homogeneous distributions of moisture within the specimens was allotted prior to the start of the compression tests. The applied total stress of the specimens was increased with increments to the values of 1 to $6,25,50,100,200$ and $400 \mathrm{kPa}$. Increment times between 12 and 24 hours (depending on the texture of the soils) were allotted for each load/stress step.

Table 1. Geotechnical properties of the investigated till soils.

\begin{tabular}{|c|c|c|}
\hline Properties & $\mathbf{o M}$ & $\mathbf{m M}$ \\
\hline Gravel, > 2 mm (wt.\%) & 2.85 & 4.72 \\
\hline Sand, $0.063-2 \mathrm{~mm}$ (wt.\%) & 50.98 & 57.08 \\
\hline Silt, $0.002-0.063 \mathrm{~mm}$ (wt.\%) & 43.20 & 37.39 \\
\hline Clay, $<0.002 \mathrm{~mm}($ wt.\%) & 2.97 & 0.81 \\
\hline Porosity $n(-)$ & 0.281 & 0.258 \\
\hline Solids specific gravity $G_{s}(-)$ & 2.650 & 2.696 \\
\hline Bulk dry density $\rho_{d}\left(\mathrm{~g} \mathrm{~cm}^{-3}\right)$ & 1.905 & 2.000 \\
\hline Natural gravimetric water content $w_{n}(\%)$ & 14.68 & 9.52 \\
\hline Liquid limit $L_{L}(\%)$ & $\mathrm{NA}^{(1)}$ & $\mathrm{NA}^{(1)}$ \\
\hline Plastic limit $P_{L}(\%)$ & $\mathrm{NA}^{(1)}$ & $\mathrm{NA}^{(1)}$ \\
\hline Plasticity index $P_{I}(\%)$ & $\mathrm{NP}^{(2)}$ & $\mathrm{NP}^{(2)}$ \\
\hline Grain diameter at $10 \%$ passing $D_{10}(\mathrm{~mm})$ & 0.0085 & 0.014 \\
\hline Grain diameter at $50 \%$ passing $D_{50}(\mathrm{~mm})$ & 0.070 & 0.100 \\
\hline Coefficient of uniformity $C_{u}(-)$ & 10.588 & 10.000 \\
\hline Coefficient of curvature $C_{c}(-)$ & 2.092 & 1.127 \\
\hline $\begin{array}{l}\text { Dry effective thermal conductivity } \lambda d r y \\
\qquad\left(\mathrm{~W} \mathrm{~m}^{-1} \mathrm{~K}^{-1}\right)^{(3)}\end{array}$ & 0.796 & 0.997 \\
\hline $\begin{array}{l}\text { Natural effective thermal conductivity } \lambda_{\text {nat }} \\
\qquad\left(\mathrm{W} \mathrm{m}^{-1} \mathrm{~K}^{-1}\right)^{(3)}\end{array}$ & 2.443 & 2.661 \\
\hline $\begin{array}{l}\text { Dry effective specific heat capacity } c d r y \\
\qquad\left(\mathrm{M} \mathrm{J} \mathrm{m}^{-3} \mathrm{~K}^{-1}\right)^{(3)}\end{array}$ & 1.533 & 1.324 \\
\hline $\begin{array}{l}\text { Natural effective specific heat capacity } c_{\text {nat }} \\
\qquad\left(\mathrm{M} \mathrm{J} \mathrm{m}^{-3} \mathrm{~K}^{-1}\right)^{(3)}\end{array}$ & 2.020 & 2.474 \\
\hline Lime content $(\%)$ & 6.67 & 12.56 \\
\hline Unified soil classification system (USCS) & $\mathrm{ML} / \mathrm{CL}^{(4)}$ & $\mathrm{SM} / \mathrm{SC}^{(5)}$ \\
\hline \multicolumn{3}{|c|}{$\begin{array}{l}\text { (1): not available, standard criteria not satisfied } \\
\text { (2): non-plastic } \\
\text { (3): effective parameters obtained using Decagon KD2 Pro transient } \\
\text { thermal needle probes } \\
\text { (4): silt or clay of low plasticity }\end{array}$} \\
\hline
\end{tabular}

Table 2. Geotechnical properties of the silty clay soil.

\begin{tabular}{|c|c|}
\hline Properties & SC-A \\
\hline Gravel, $>2 \mathrm{~mm}(\mathrm{wt} . \%)$ & 16.1 \\
\hline Sand, $0.063-2 \mathrm{~mm}(\mathrm{wt} . \%)$ & 8.8 \\
\hline Silt, $0.002-0.063 \mathrm{~mm}$ (wt.\%) & 58.2 \\
\hline Clay, $<0.002$ mm (wt.\%) & 16.8 \\
\hline Porosity $n(-)$ & 0.443 \\
\hline Solids specific gravity $G_{s}(-)$ & 2.673 \\
\hline Bulk dry density $\rho_{d}\left(\mathrm{~g} \mathrm{~cm}^{-3}\right)$ & 1.489 \\
\hline Natural gravimetric water content $w_{n}(\%)$ & 16.8 \\
\hline Liquid limit $L_{L}(\%)$ & 34.6 \\
\hline Plasticity index $P_{I}(\%)$ & 14.81 \\
\hline Dry effective thermal conductivity $\lambda_{d r y}\left(\mathrm{~W} \mathrm{~m}^{-1} \mathrm{~K}^{-1}\right)^{(1)}$ & 0.184 \\
\hline Sat. effective thermal conductivity $\lambda_{\text {sat }}\left(\mathrm{W} \mathrm{m}^{-1} \mathrm{~K}^{-1}\right)^{(1)}$ & 1.389 \\
\hline Unified soil classification system (USCS) & $\mathrm{CL}^{(2)}$ \\
\hline
\end{tabular}

${ }^{(1)}$ : effective parameters obtained using Decagon KD2 device

${ }^{(2)}$ : clay of low plasticity 

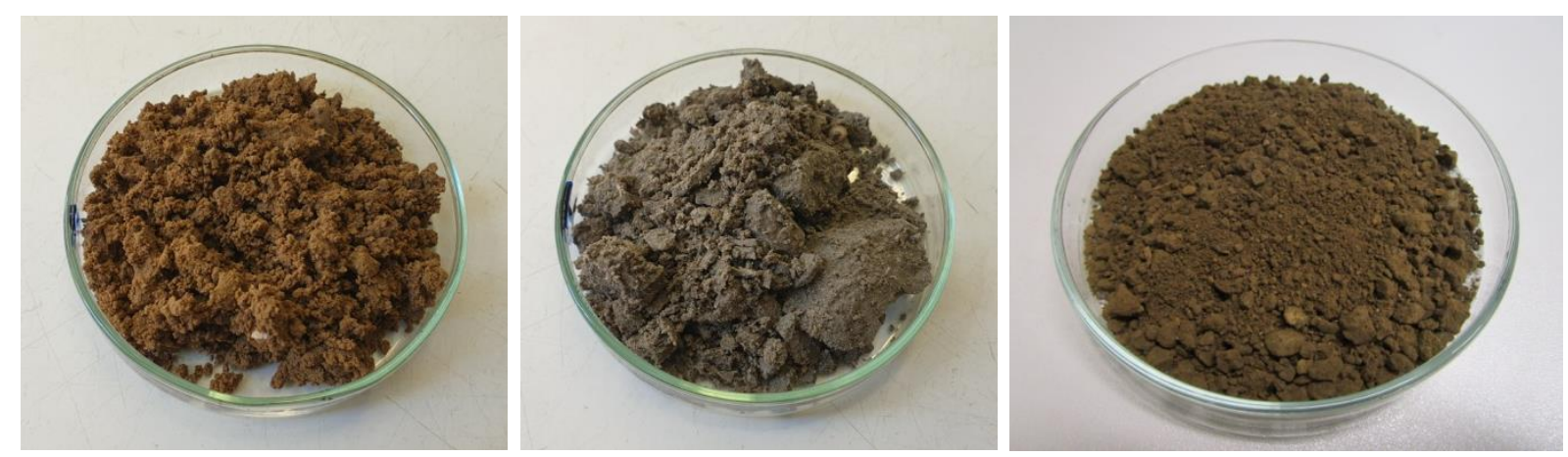

Fig. 1. Samples of: (left) oM, (middle) mM and (right) SC-A, soils.
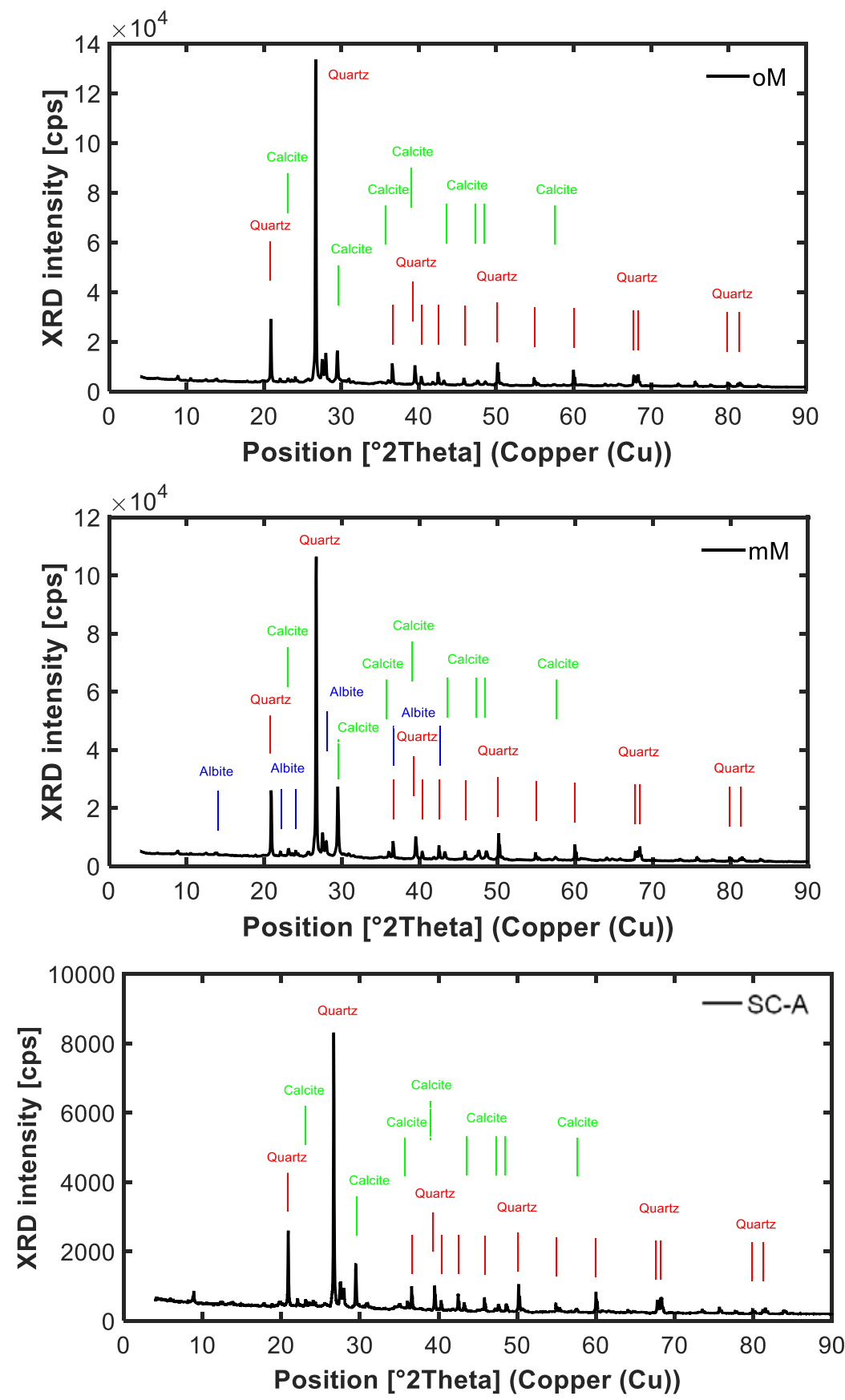

Fig. 2. XRD diagrams of: (top) oM, (middle) $\mathrm{mM}$ and (bottom) SC-A, soils. 

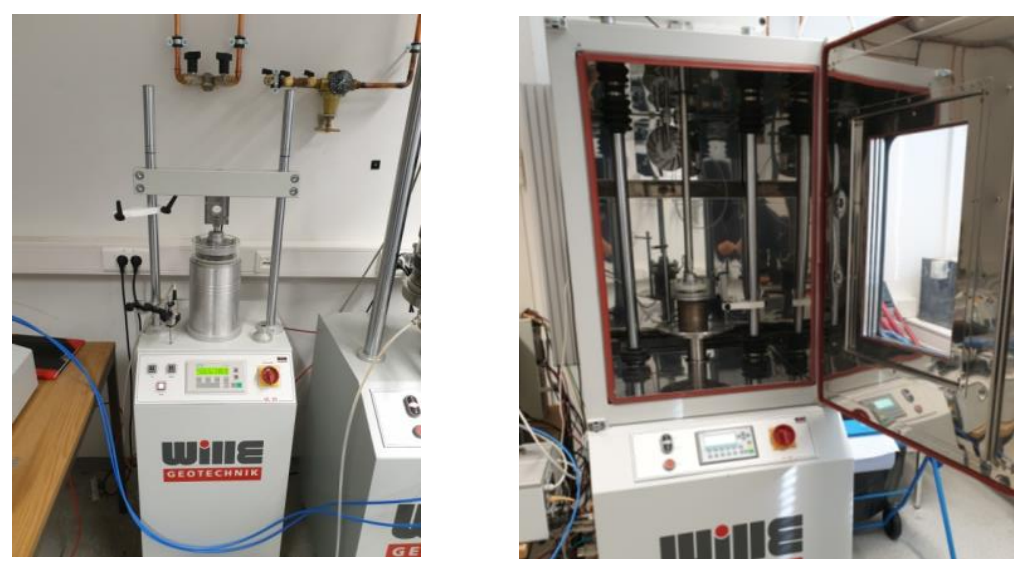

Fig. 3. Oedometric testing equipments for: (left) room temperature and (right) elevated temperatures.

The specimen deformations were recorded via TRS0025/TRS-0050 linear transducers with defined electrical ranges of $25 \mathrm{~mm} / 50 \mathrm{~mm}$, independent linearities of $0.2 \% / 0.15 \%$ and repeatabilities of $2 \mu \mathrm{m}$, respectively. The applied vertical stress and specimen deformation data were monitored and stored with a PC and a data acquisition unit at a data logging interval of 1 minute.

After the completion of the tests, the values of linear shrinkages associated with the heating tests of each soil specimen were calculated as the changes in the linear vertical strain values of the soils recorded during the minimal contact load (first load step) of 1 to $6 \mathrm{kPa}$. During the application of this first load step, the stress level applied to the specimen is too low to cause sample deformation, but as can be seen in the stress-strain plots presented in section 3.2 (Fig. 5) of this study, most of the shrinkage and drying processes of the samples occur during this stage due to the heating of the soils.

\section{Results and discussion}

The experimental results of the moisture and temperature dependent one dimensional compression tests of the soils are presented in this section.

\subsection{Effect of moisture content on the compressibility of the soils}

Figure 4 presents the results of the oedometer tests on the soils at natural and fully saturated moisture conditions. The stresses mentioned in this study are all total stresses, and the exact effective stresses are not determined as the pore-water pressures were not measured during the tests performed at unsaturated and saturated conditions.

However, as all the tests were conducted under fullydrained conditions and as sufficient time was allotted for each load step to stabilize and consolidate the soil, the generation of excess pore-water pressure in the samples can be assumed insignificant by the end of the application of each load step. At this stage the total and effective stresses acting on the soil can be assumed to be equal.
The experimental results exhibit a general increase in the compressibility of all three soils with an increase in moisture content. Fine- and medium- grained soils at high moisture condition are characterized by the presence large quantities of water in their void space as well as the presence of water molecules at the inter-plane space of the clay minerals (Schafer \& Singer 1976 [7]; Low \& Margheim 1979 [8]; Parker et al. 1982 [9]). Upon the application of loads, the soil gets compressed and water is generally expelled from the void space, in a process typically called consolidation.

The degree of compression is highly associated with the amount of water in the voids or the degree of saturation of the soil, and usually decreases with soil dryness. Moreover, at low moisture content condition, the degree of friction and interlocking between the quartz, calcite and albite dominated soil grains is high and hence the resistance to compression is maximum. With an increase in moisture content of the soil however, the individual grains are lubricated, lowering the frictional forces bonding the grains, resulting in higher deformations upon the application of stress.

When comparing the increase in compressibility with increase in moisture content of each soil for the given stresses, SC-A has a comparatively higher increase in compressibility followed by oM due to its comparatively finer-grain size or texture and clay content as compared to that of $\mathrm{mM}$.

\subsection{Effect of temperature on the compressibility of the soils}

Figure 5 depicts the results of the oedometer tests on the soils (initially at natural moisture content conditions) at medium temperatures of 20,40 and $60^{\circ} \mathrm{C}$.

The experimental results show that the compressibility of all soils decreases with an increase in the medium temperature, mainly due to the removal of moisture content or drying of the specimens upon heating, and the subsequent shrinkage and reduction of soil porosity, resulting in a more stiff and deformation resistant medium.

The moisture migration and drying as well as shrinkage and the formation of tensile desiccation cracks 
in the specimens upon heating can be visibly seen by comparing the images of the specimens taken before and after the temperature controlled loading tests (Figs. 6 to 8 ). During the process of drying of the soil due to heating, its volume decreases by shrinkage, and desiccation cracks form due to excessive internal stresses in the shrunken soil. The cracks usually form along preexisting planes of weakness in the soil skeleton.
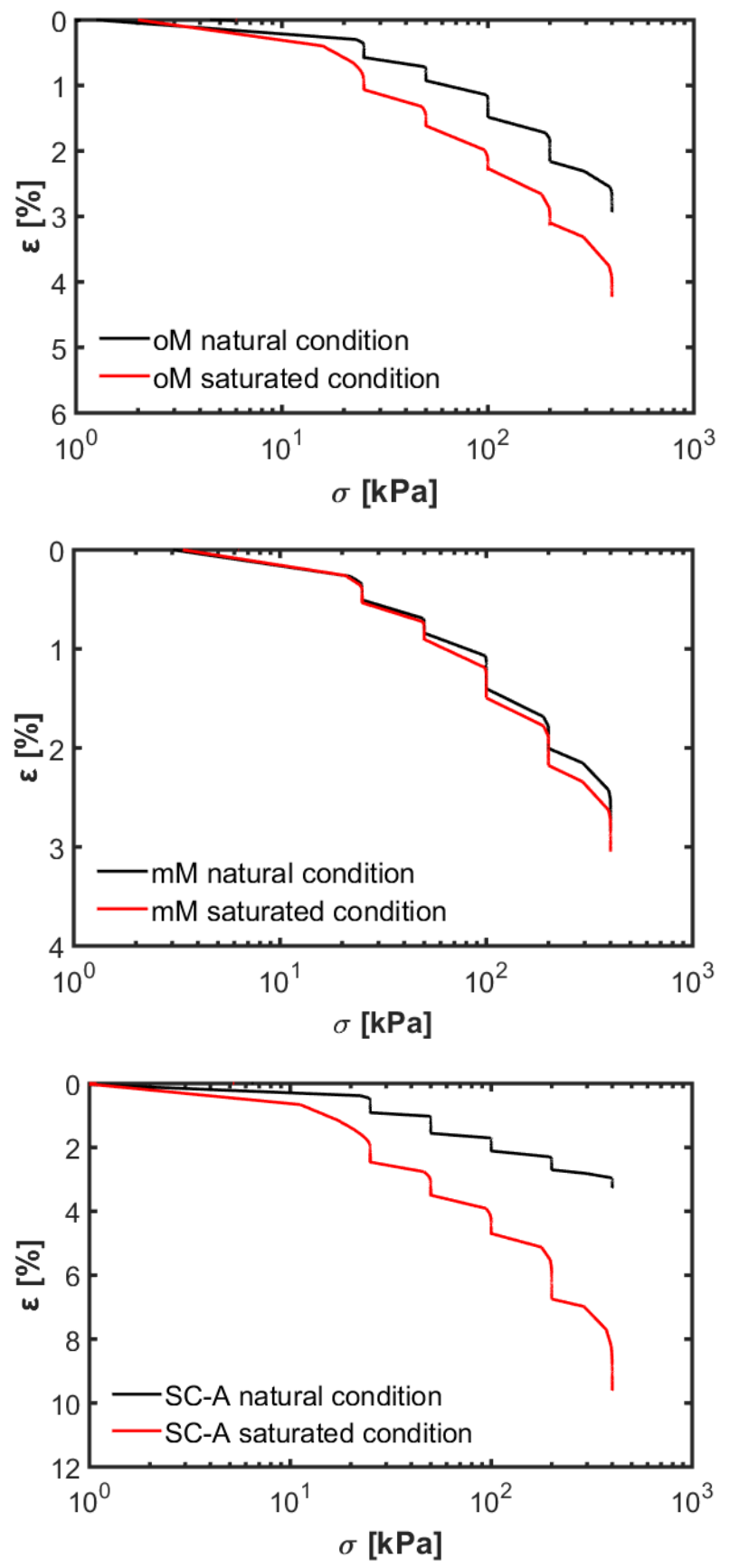

Fig. 4. One dimensional compression test results at different levels of saturation for: (top) oM, (middle) $\mathrm{mM}$ and (bottom) SC-A, soils.

As expected, the linear shrinkage strain $\varepsilon_{s h}$ observed upon heating of the soil specimens generally increases with the magnitude of the applied temperature, with the highest $\varepsilon_{s h}$ values recorded for the loading tests at $60^{\circ} \mathrm{C}$ as shown in Table 3. When comparing the degrees of shrinkage strains $\varepsilon_{s h}$ recorded for the three soil types, SC-A exhibits the highest $\varepsilon_{s h}$ followed by oM, due to its comparatively finer-grain size or texture, higher clay content and higher initial volumetric water content which is driven out during the heating process of the specimen, as compared to that of $\mathrm{mM}$.

Table 3. Recorded shrinkage strains $\varepsilon_{s h}$ of the soils upon loading test at $60^{\circ} \mathrm{C}$.

\begin{tabular}{c|c}
\hline Soil & $\boldsymbol{\varepsilon}_{\boldsymbol{s h}} \mathbf{( \% )}$ \\
\hline $\mathrm{oM}$ & 0.495 \\
$\mathrm{mM}$ & 0.198 \\
SC-A & 0.775 \\
\hline
\end{tabular}
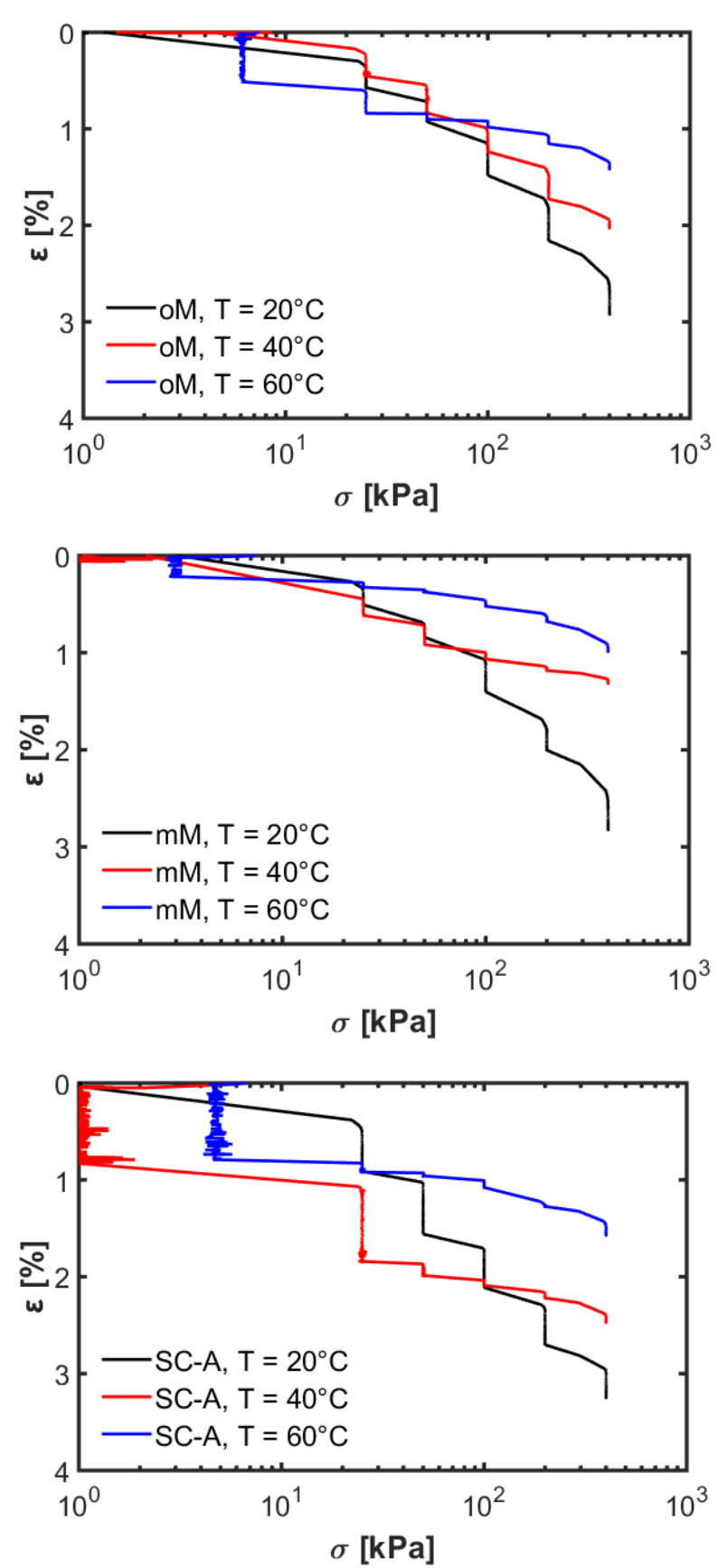

Fig. 5. One dimensional compression test results at different temperatures for: (top) oM, (middle) $\mathrm{mM}$ and (bottom) SC-A, soils. 
When comparing the linear shrinkage strains obtained in this study with the literature (Cerato \& Lutenegger 2006 $[10])$, the shrinkage values from our study are much lower than those measured by Cerato and Lutenegger. The technique of measuring the linear shrinkage followed in our study is comparable to that used by Cerato and Lutenegger, as both procedures involve the recording of the sample shrinkage strain during its drying or shrinkage process due to the application of heat to the soil.

Cerato and Lutenegger studied the linear shrinkage (LS) of four natural and pure clays following the standards of BS-1377 (1990) [11]. For a white marsh residual soil from Maryland, USA, which out of the four soils they considered, has the closest properties with the silty clay soil from our study, they measured a linear shrinkage value of $10.3 \%$. However, it should be noted that the shrinkage test performed on the white marsh soil by Cerato and Lutenegger had an initial water content of above $50 \%$, which during the shrinkage process lowered to around near dry condition. Moreover, the shrinkage strain of the specimen largely occurred during the lowering of moisture content of the soil from around 40 to $18 \%$, below which no significant shrinkage was observed. Considering this fact, and that the silty clay soil in our study has an initial starting water content of $16.8 \%$ for the heating tests, the differences in the obtained linear shrinkage values are to be expected.

The observed formation of tensile micro- and macrocracks and significant shrinkage behavior of the fineand medium- grained soils highlight the importance of assessing soils for use in heat storage systems particularly at or near areas close to the heat exchanger. The exposure of such soils which are usually at high degrees of moisture saturation to high temperatures can rapidly cause the drying and shrinkage processes to occur causing the formation of significant tensile desiccation cracks in the heat storage medium, and notably lowering the effective thermal conductivity of the medium and the overall system efficiency.
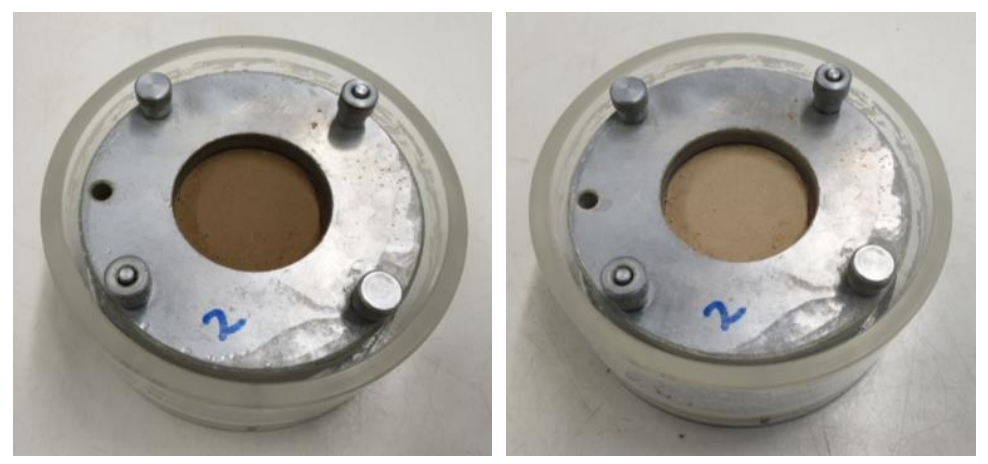

Fig. 6. Images of the oM specimen: (left) before and (right) after loading test at $60^{\circ} \mathrm{C}$.
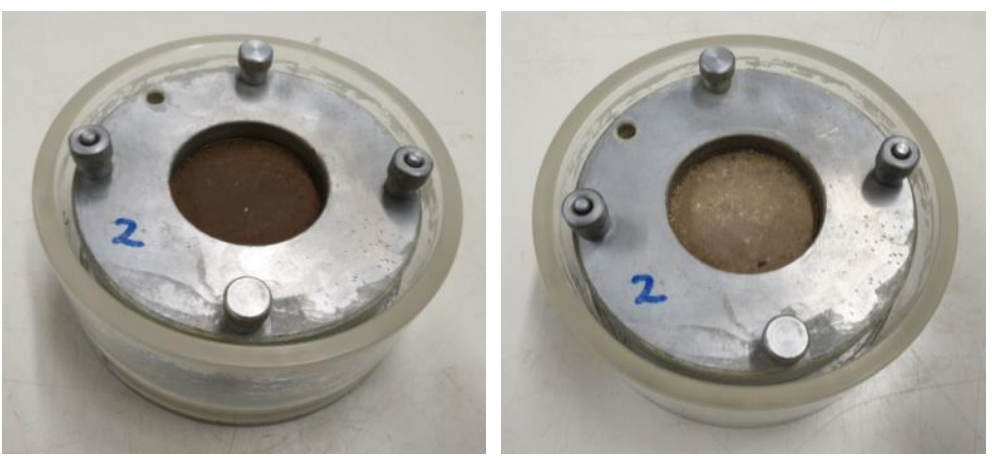

Fig. 7. Images of the SC-A specimen: (left) before and (right) after loading test at $60^{\circ} \mathrm{C}$.
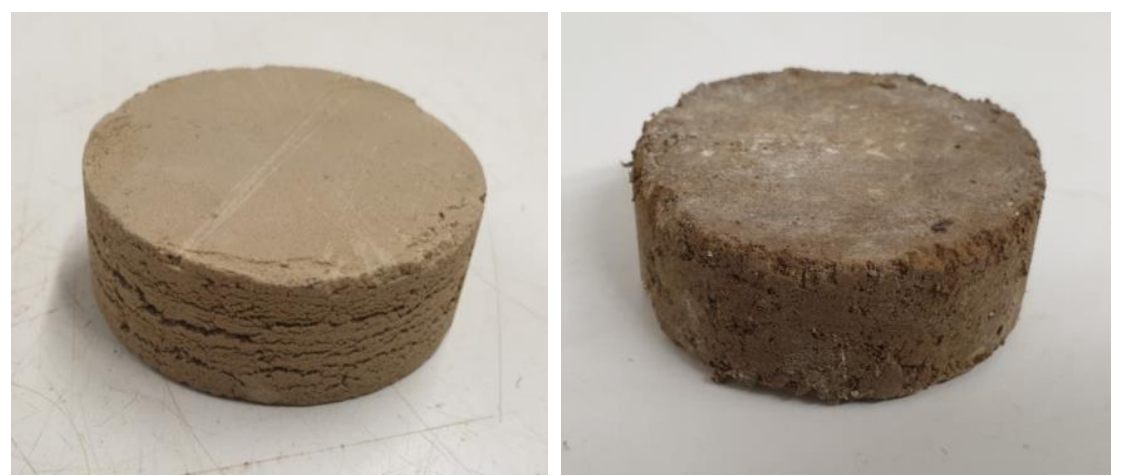

Fig. 8. Formation of micro- and macro- primary tensile cracks in: (left) oM and (right) SC-A, specimens after loading test at $60^{\circ} \mathrm{C}$. 


\section{Conclusions}

Moisture content and temperature affect the mechanical performance of soils used as heat storage media, and hence require adequate attention prior to the design and implementation of solid sensible and borehole thermal energy storage systems, which are generally designed at or below the ground level with load bearing capabilities, and where moisture content fluctuates frequently due to the rise and fall of the ground water table level.

On this basis, the mechanical behavior of three fineand medium- grained soils was analyzed at different moisture contents and temperature conditions, in view of their usage as heat storage media. A pronounced reduction in stiffness was observed with an increase in moisture content of the soils, mainly due to the presence of large quantities of water in the void space as well as the inter-plane spaces of the clay minerals, and also by the reduction of inter-granular frictional forces by the lubricating effect of the additional water molecules. However, an increase in soil stiffness or a reduction of compressibility of the soils was observed with an increase in medium temperature, mainly due to the removal of moisture content or drying of the specimens upon heating, and the subsequent shrinkage and reduction of soil porosity, resulting in a more stiff and deformation resistant medium.

In spite of the increase of mechanical stability of the soils upon temperature increase, excessive shrinkage and formation of tensile desiccation micro- and macro-cracks due to excessive internal stresses was evident particularly by heating at $60^{\circ} \mathrm{C}$. Such development can have a negative impact especially at areas close to the heat exchanger, where high temperatures are expected during the charging of the heat storage system. Formation of tensile cracks can notably lower the effective thermal conductivity of the heat storage soils and the overall system efficiency.

\section{Acknowledgements}

The authors would like to acknowledge the financial support provided by the German Federal Ministry for Economic Affairs and Energy (BMWi) under the Grant number 03ET6122A (Project ANGUS II) as well as the support of Project Management Jülich. We are grateful to Kerstin Meier zu Beerentrup, Angewandte Geologie Group, Kiel University, for her help in collecting the till samples from the field site in Heiligenhafen. We are also grateful to Dr. Hans-Jürgen Stephan, formerly of Landesamt für Natur und Umwelt Schleswig-Holstein, Flintbek, Germany, for his support in identifying the glacial till sampling locations in Heiligenhafen. We would also like to thank Brendan Ledwig, Experimentelle und Theoretische Petrologie, Kiel University, for his support in analyzing the XRD measurements of the soils.

\section{References}

1. D. Laing, W-D. Steinmann, R. Tamme, C. Richter. (2006). Solid media thermal storage for parabolic trough power plants. Solar Energy 80:10, 1283 1289

2. D. Laing, C. Bahl, T. Bauer, M. Fiss, N. Breidenbach, M. Hempel. (2012). High-temperature solid-media thermal energy storage for solar thermal power plants. Proceedings of the IEEE 100:2, 516524

3. H. Hailemariam, D. Schwindrofska, F. Wuttke. (2019). Mechanical stability of cemented porous heat storage media. López-Acosta, N.P. et al. ed. XVI Pan American Conference on Soil Mechanics and Geotechnical Engineering, 2867-2872, N - IOS Press, Cancun, Mexico

4. C. Doughty, A. Nir, C.F. Tsang, G.S. Bodvarsson (1983). Heat storage in unsaturated soils: Initial theoretical analysis of storage design and operational method. Proceedings of the International Conference on Subsurface Heat Storage in Theory and Practice, Stockholm

5. G.K. Hart \& W.I. Whiddon. (1984). Ground source heat pump planning workshop. Summary of Proceedings, Palo Alto: Electric Power Research Institute, EPRI Report RP 2033-12

6. H.-J. Stephan. (1985). Exkursionsführer Heiligenhafener 'Hohes Ufer'. Der Geschiebesammler 18:3, 83-99

7. J.C. Schafer \& M.J. Singer. (1976). Influence of physical and mineralogical properties on swelling of soils in Yolo County, California. Soil Science Society of America Journal 40, 557-562

8. P.F. Low \& J.F. Margheim. (1979). The swelling of clay: I. Basic concepts and empirical equations. Soil Science Society of America Journal 43, 473-481

9. J.C. Parker, D.F. Amos, L.W. Zelazny. (1982). Water adsorption and swelling of clay minerals in soil systems. Soil Science Society of America Journal 46, 450-456

10. A.B. Cerato \& A.J. Lutenegger. (2006). Shrinkage of clays. Fourth International Conference on Unsaturated Soils, American Society of Civil Engineers, Carefree, Arizona, USA, April 2-6, 2006

11. BS-1377. (1990). Soils for civil engineering purposes. British Standards Institute, London, UK 